\title{
Application of low impact development technology in rainwater drainage system reconstruction project
}

\author{
Pengbo Hu${ }^{1,2}$. Yue $\mathrm{Ma}^{3} \cdot$ Huifeng Xue ${ }^{1} \cdot$ Feng Zhang ${ }^{1}$
}

Received: 18 August 2017 / Revised: 25 September 2017 / Accepted: 22 October 2017 / Published online: 4 December 2017

(C) The Author(s) 2017

\begin{abstract}
Urban roadway contributing much to the runoff and non-point source pollution in modern cities is one of the key objectives when conducting stormwater management in Sponge City construction, which was recently launched by Chinese government. In the present case study, Qinhuang Avenue (length $\times$ width $=2.4 \mathrm{~km} \times 80 \mathrm{~m}$ ) from Xixian New Area in northwest China was chosen as the research objective. The current limitations within the rainwater drainage system of Qinhuang Avenue were analyzed as well as its environmental background (such as the structure and permeability of the wet-sunk loess). Under the premise of maintaining roadway safety and taking the horizontal and vertical line into consideration, low impact development (LID) technology was applied for the design and planning of the reconstruction project according to the principle and requirement of LID technology. The implementation results of the project indicated that waterlogging and flooding issues in the object region were obviously resolved and environmental capacity was improved as evidenced by the reduced volume, peak value and contaminants concentration of total runoff.
\end{abstract}

Keywords Sponge City · Low impact development . Wet-sunk loess - Total runoff control · Runoff pollution control

Feng Zhang

tfnew21@sina.com

1 Northwestern Polytechnical University, Xi' an, China

2 Management Committee of Fengxi New City in Xixian New Area, Xi' an, China

3 Sponge City Center of Fengxi New City in Xixian New Area, Xi'an, China

\section{Introduction}

Recently, due to the global climate change, the frequency, intensity, and distribution spans of extreme weather conditions of extreme weather have increased, especially short term rainstorms [1]. As a result, large amounts of rainwater accumulate in cities leading to serious problems, such as urban waterlogging and flooding, which imposed threats to urban safety, the economy, and people's daily lives [2]. For example, the urban waterlogging after rain has become the most severe and universal phenomenon, and hundreds of cities have suffered the disasters almost every year since 2008 according to the statistical data from the Office of State Flood Control and Drought Relief Headquarters of China [3].

As known, urban drainage systems were used to deal with these issues, but also faced great challenges such as the increase in extreme events and impervious surfaces exceeding the limited capacity of the drainage systems, especially the obsolete systems still in use. In instance, in over $90 \%$ of cities in China, the current design conception of stormwater drainage system was based on the fast discharge idea and focused on the construction of gray infrastructures [4], which was costly and hard to catch up with the rapid expansion speed of city and impervious surface. As a result, numerous man-power and investments were cost for this pollution control on constructions of sewage treatment plants and development of their treatment technologies [3]. It should be noted that the usage of impervious surfaces are still increasing due to the speeding of urbanization, which became one of the most important factors resulting in severe hydraulic problems and increased the possibility of urban flooding during storm events [5,6].

Furthermore, urbanization process converted some "natural" lands (e.g., forest and grasslands) for residential or commercial use, which altered the water balance and 
increased areas with impervious surfaces [2]. Thus the functions including rainwater absorbing, maintaining, filtering or purifying by "natural" lands were largely lowered down. So it is urgent to rethink the conventional urban construction mode during the urbanization process and develop a more green and environmental-friendly strategy for sustainable urbanization.

Under this condition, the concept of Sponge City was first proposed in 2012 Low-Carbon Urban Development and Technology Forum, while in 2013 Sponge City construction was firstly raised by Xi Jinping, President of P.R. China. From then on, 16 and 14 urban districts across the country were chosen as the first and second batches of pilot Sponge Cities respectively, including large cities as well as middle and small cities under various climate conditions [3]. The construction guideline of Sponge City in China-low impact development of stormwater system was in timely proposed in 2015, in which besides the technologies such as low impact development (LID), the entire measures of Sponge City construction should contain the gray infrastructure system for the midway control (e.g., sewage drainage network, pump) and the surrounding landscape (e.g., river, wetland, forest, farmland and lake) as well [3]. LID reintroduces the hydrologic and environmental functions that are altered with conventional storm water management. LID helps to maintain the water balance on a site and reduces the detrimental effects that traditional end-of-pipe systems have on waterways and the groundwater supply. LID devices provide temporary retention areas; increase infiltration; allow for nutrient (pollutant) removal; and control the release of storm water into adjacent waterways.

Also, it was well recognized that urban roadway contributed much to the runoff and non-point source pollution in modern cities $[7,8]$, and also urban roadway was one of the key objectives when conducting storm water management in Sponge City construction. Thus, this study presented a case project regarding the design, reconstruction and implementation performance of an avenue rainwater drainage system using LID technology $[9,10]$, locating in an important demonstration area of Sponge City construction in northwest China. The case study was expected to provide some useful suggestions for the future Sponge City construction in China and other developing countries.

\section{Methods}

\subsection{Brief introduction of the project}

\subsubsection{Project overview}

Qinhuang Avenue is one of the urban arteries located at the core area of Fengxi New City in Xixian New Area, Xi'an, China. It starts from Tongyi Road in the north to Hengba Road in the south. The avenue has a length of $2.43 \mathrm{~km}$ and a width of $80 \mathrm{~m}$, as well as a greenbelt of $35 \mathrm{~m}$ apart from both sides of the road. The construction of the avenue begins in 2011 and completes in 2012, from then on Qinhuang Avenue functions as an important regional transportation pivot. In the latter half of the year 2015, the reconstruction project is launched according to the requirement of Sponge City construction planning.

\subsubsection{Basic conditions analysis}

- Meteorological and rainfall conditions

The Fengxi New City is located in the temperate and continental semi-arid climate zone. Under the combined effects of atmospheric circulation and topography, it is hot and rainy in summer while cold and dry in winter. The annual mean precipitation in this area is $520 \mathrm{~mm}$, in which rainfalls from July to September account for more than $50 \%$ of the total amount mainly in the form of rainstorm. So it is easy to induce natural disasters including flood, waterlogging, water and soil erosion, and etc.

\section{- Hydrogeological condition}

Regional groundwater is mainly replenished by atmospheric precipitation and underground runoff, with the Weihe River and the Fenghe River as the main replenishing sources. The groundwater flows from the south to the north, and the buried depth was in the range of 7.9-16.1 m but showing a slow declining tendency annually $(0.5-1.0 \mathrm{~m} / \mathrm{year})$. The groundwater mainly contains carbonate, sulfate, calcium, potassium and sodium. According to the report of geotechnical engineering investigation, it was noted that the proposed site is non-self-heavy wet and loess ground with a level of first class. Loess soil and silty clay content is higher in the upper layer of the parent soil resulting in a poor infiltration performance that was not suitable for direct rainwater infiltration.

\section{- Underlying surface condition}

Before reconstruction, the schematic diagram of the crosssection of the Qinhuang Avenue was shown as Fig. 1, while the classification, area and runoff coefficient of the underlying surface was presented in Table 1.

- Terrain elevation condition

Qinhuang Avenue has a flat topography with the lowest ground elevation of $387.43 \mathrm{~m}$ and highest ground elevation of $387.43 \mathrm{~m}$, the maximum longitudinal grade of $0.75 \%$, 


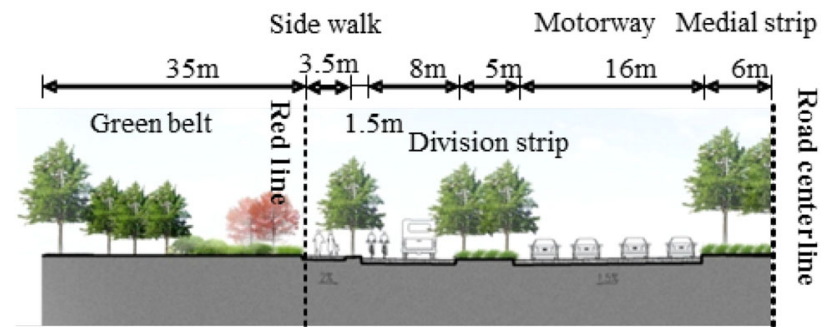

Fig. 1 Road cross-section of Qinhuang Avenue before reconstruction

Table 1 Underlying surface conditions of Qinhuang Avenue before reconstruction

\begin{tabular}{lcll}
\hline $\begin{array}{l}\text { Types of underlying } \\
\text { surface }\end{array}$ & $\begin{array}{l}\text { Area } \\
\text { (ha) }\end{array}$ & $\begin{array}{l}\text { Occupied } \\
\text { percentage } \\
\eta(\%)\end{array}$ & $\begin{array}{l}\text { Rainfall runoff } \\
\text { coefficient } \varphi\end{array}$ \\
\hline Bituminous pavement & 13.44 & 70 & 0.9 \\
Rigid pavement & 2.06 & 10.7 & 0.8 \\
Greenbelt & 3.70 & 19.3 & 0.15 \\
& 19.2 & 100 & $\begin{array}{l}0.745 \\
\text { (Calculated) }\end{array}$ \\
\hline
\end{tabular}

the minimum longitudinal slope of $0.35 \%$ and the minimum slope of $190 \mathrm{~m}$. On the one hand, the longitudinal slope will induce the rainfall flow to the down-fold and easily cause waterlogging when encountering insufficient transmittability of the pipe network; on the other hand, the longitudinal slope will adversely affect the of regulation and storage functions of the LID facilities.

\section{- Pipe network condition}

The separated drainage system was used, while the rainwater pipe network has been completed to collect the runoff from the road and surrounding surface. The design parameters were as follows: 2-year return period, pipeline buried depth of 2-4 m, pipe diameter of 500-1000 mm, service area of $63 \mathrm{hm}^{2}$, and rainstorm intensity formula as:

$q=\frac{2785.833 Y 1+1.16581 g P Y}{Y t+16.813 Y^{0.9302}}$

In which, $\mathrm{q}$ means the rainstorm intensity; $\mathrm{P}$ means the return period; $t$ means the duration of the rainfall; $t_{1}$ means the catchment time; $t_{2}$ means the flowing time of rainwater in the pipe.

- Rainwater discharging and receiving water body

Rainwater pipe network of the Qinhuang Avenue belongs to two drainage partitions (presented in Fig. 2). In the north part of Qinhuang Avenue, rainwater was collected and elevated by Fengjing Road pump station to Weihe River; for the

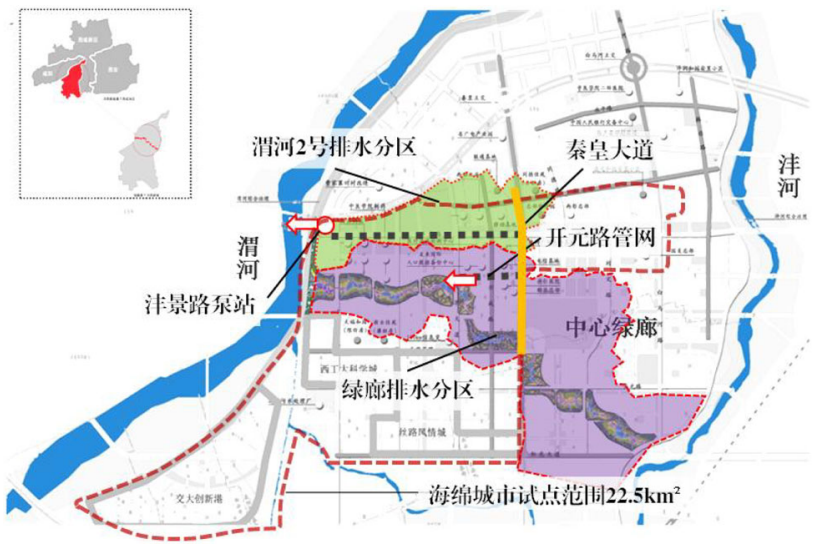

Fig. 2 Rainwater drainage organization of Qinhuang Avenue

south part of Qinhuang Avenue, rainwater was collected and discharged to a branch of Weihe River.

\subsubsection{Current issues and requirements}

- Regional drainage relying on pump station with high energy consumption

In the north part of Qinhuang Avenue, the drainage catchment area is $3.07 \mathrm{~km}^{2}$; the end of the pipe network had a burial depth of $9.42 \mathrm{~m}$, which is lower than water level Weihe River for about $5.4 \mathrm{~m}$ and lower than the bench land for about $8.5 \mathrm{~m}$, thus the rainwater cannot be discharged into Weihe River by gravity flow but be expelled by pump station. The planned rainwater pump station has a design flow rate of $11.84 \mathrm{~m}^{3} / \mathrm{s}$, and the pump shows the specified flow rate, pump lift, motor power and working voltage of $9000 \mathrm{~m}^{3} / \mathrm{h}$. $16.5 \mathrm{~m}, 630 \mathrm{~kW}$ and $10 \mathrm{kV}$, respectively. According to the parameters, when the estimated discharging volume of the annual runoff is $8.94 \times 10^{5} \mathrm{~m}^{3}$, the energy consumption is calculated to be $6.26 \times 10^{4} \mathrm{~kW} \mathrm{~h}$.

- High water quality requirement of receiving water bodies and high risks caused by seasonal diffuse pollution

For the south part of Qinhuang Avenue, rainwater was collected and discharged to a branch of Weihe River, which is provided with the functions of rainwater regulation, ecological corridor and water resource usage. Because the rainwater carries large amount of pollutants (such as suspended solids, COD, total nitrogen, total phosphorus, heavy metal and oils), it is easy to induce water environment pollution and ecosystem destruction.

- Frequent waterlogging due to the limitations of conventional drainage system 
Qinhuang avenue has a large catchment area, thus after a storm rain lots of rainwater are collected within a short time. However, due to the facts that the green belt is higher than the road bed and many low-lying exists along the avenue, rainwater cannot be reduced by infiltration and storage of green belt and cause waterlogging issues affecting traffic safety.

- Special geologic environment causing great challenges to the implementation of LID

On the one hand, soil in the Qinhuang Avenue located area has poor infiltration ability which influences the rainwater storage and regulation of LID facilities, thus how to improve the soil permeability and control pollution is urgently to be resolved. On the other hand, the soil in this region is a nonself-heavy wet and loess ground with the level of first class. When encountering rainwater the destroy of soil structure and sudden reduction of its carrying capacity will occur, thus bringing great challenges to the structure safety of the infrastructures using LID technology.

\subsection{Determination of the expected goal for reconstruction project}

\subsubsection{Core goals: determination of the annual runoff volume control rate}

- Runoff volume control

According to the related requirements of Sponge City construction announced by the government, the runoff volume control rate of Fengxi New City should be controlled in the range of $80-85 \%$. Given the hydrological and geologic features of Qinhuang Avenue and regional planning, the runoff volume control rate of Qinhuang Avenue is set to $85 \%$ with a designed precipitation of $19.2 \mathrm{~mm}$ (shown in Fig. 3).

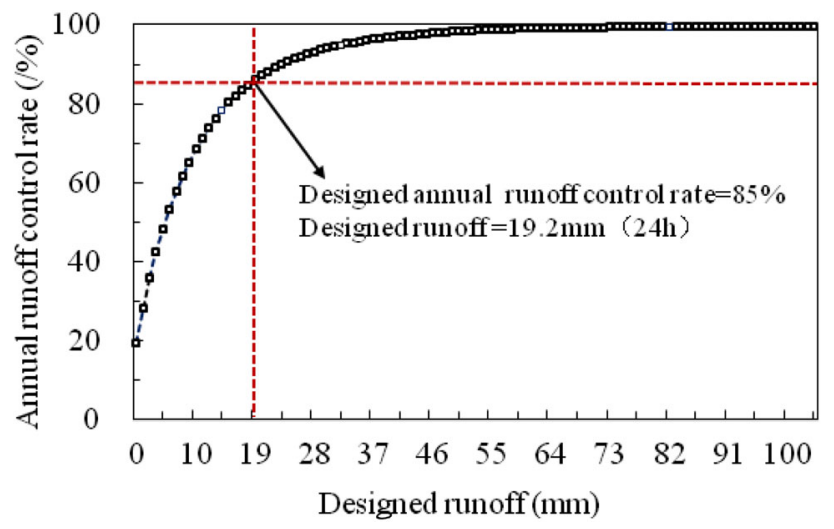

Fig. 3 Relationship between the design rainfall depth and control ratio of annual rainfall in Fengxi New City
- Runoff pollution control

According to the water quality requirements of receiving water bodies (forth class standard of surface water in China), especially for the branch of Weihe River in the south part, the discharged rainwater quality should better than abovementioned criteria. Based on the demand of above core goals for LID facilities design, considering its own characteristics of Qinhuang Avenue, the reconstruction goals are set as follows: (1) The runoff volume control rate is $85 \%$ corresponding to a designed precipitation of $19.2 \mathrm{~mm}$; (2) Effectively coping with the storm water of 50-year return period by integration of LID facilities, pipe network and runoff discharging system; (3) Runoff pollution control rate should exceed $60 \%$ (taking total suspended solids as a representative parameter).

\section{Results and discussion}

\subsection{Project design and implementation}

\subsubsection{Designed regulation volume}

(1) Dividing sub-catchments

Based on the terrain analysis, there are 6 high spots and 5 low spots within the Qinhuang Avenue located area, thus the area can be divide into 5 sub-catchments to facilitate relatively independent regional control (shown in Fig. 4). The basic conditions in terms of road cross-section, underlying surface are almost the same among different sub-catchments.

(2) Designed regulation volume of sub-catchments The calculation method is as follow:

$v_{x}=10 H \varphi F$

In which, $\mathrm{V}_{\mathrm{x}}$ means designed regulation volume; $\mathrm{H}$ means designed precipitation (19.2 $\mathrm{mm}) ; \varphi$ means integrated runoff coefficient; F means catchment area, $\mathrm{hm}^{2}$.

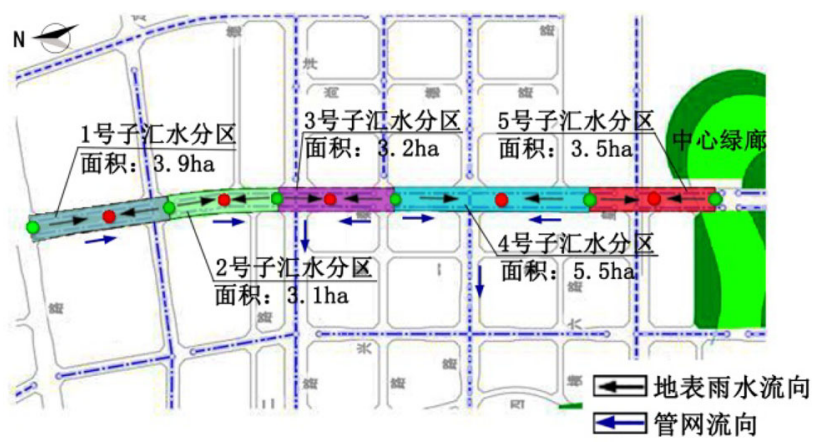

Fig. 4 Partitioning of rainwater collection zones for Qinhuang Avenue 
Table 2 Retention and storage volume of No. 1 rainwater collection zone

\begin{tabular}{lllr}
\hline Types of underlying surface & $\mathrm{F}(\mathrm{ha})$ & $\varphi$ & $\mathrm{V}_{x}\left(\mathrm{~m}^{3}\right)$ \\
\hline Bituminous pavement & 2.72 & 0.9 & 470.02 \\
Rigid pavement & 0.42 & 0.8 & 64.51 \\
Greenbelt & 0.35 & 0.15 & 10.08 \\
& & 0.813 & 544.61 \\
\hline
\end{tabular}

Table 3 Hydrological calculation results of rainwater collection zones

\begin{tabular}{llrr}
\hline Sub-catchment & $\mathrm{F}(\mathrm{ha})$ & $\mathrm{V}_{x} / \mathrm{m}^{3}$ & $\mathrm{~V}_{k} / \mathrm{m}^{3}$ \\
\hline No. 1 & 3.9 & 571.8 & 594.5 \\
No. 2 & 3.1 & 460.7 & 464.8 \\
No. 3 & 3.2 & 477.8 & 482.2 \\
No. 4 & 5.5 & 817.9 & 820.5 \\
No. 5 & 3.5 & 523.4 & 525.5 \\
Total & & 2851.6 & 2887.5 \\
\hline
\end{tabular}

Based on the calculation methods, the No. 1 sub-catchment is taken as an example to count the required regulation volume as presented in Table 2. In this work the runoff produced by greenbelt along the avenue is also taken into consideration. Moreover, $5 \%$ of safety margin is added, thus the final total regulation volume $\left(\mathrm{V}_{\mathrm{k}}\right)$ of No. 1 sub-catchment is $571.8 \mathrm{~m}^{3}$. The values of other sub-catchments are obtained in agree with the same calculating method (shown in Table 3).

\subsubsection{Flow chart and facility selection and layout}

During the reconstruction of Qinhuang Avenue, the main principle is to develop an integrated rainwater management system by considering the strategies of reduction from the source, transmission using pipe network and prevention of waterlogging and related disasters.

In the design of the avenue reconstruction, green belt and division strip between roadway and sidewalk are sunken. The road kerbs at low point are open to induce the rainwater from roadway and sidewalk flow into the lateral zonation. In the division strip between roadway and sidewalk, transmission grassed waterway, ecological grassed waterway and rainwater garden are installed for rainwater transmission, purification and infiltration. While for the sidewalk, the impermeable pavement is altered to permeable pavement. Above measures are used for the reduction of rainwater and involved pollutants from the source.

Within the lateral zonation, newly increased rainwater overflow ports are connected to the existed catch-basins, in order to discharge the rainwater that exceeds storage capacity of the LID facilities. In the green belt, outside of the road red

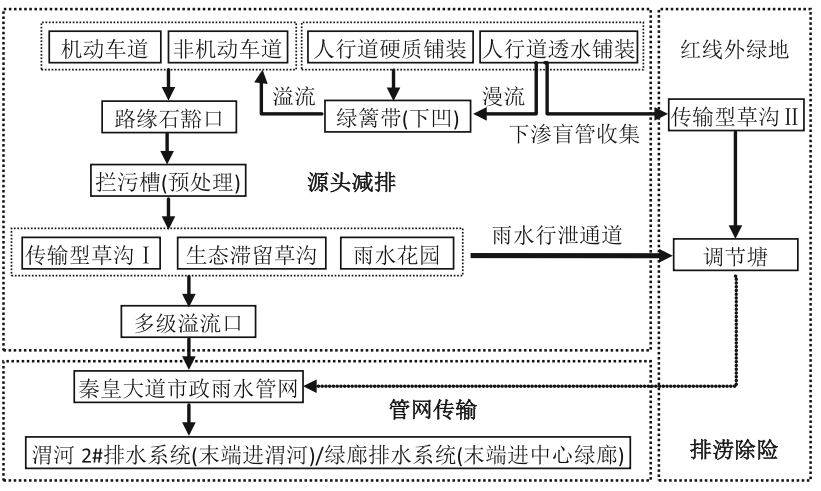

Fig. 5 Flow chart of low impact design and renovation of Qinhuang Avenue

line, transmission grassed waterway is constructed coupled with the rainpool near the places where frequent waterlogging occurs. Underground culverts are constructed under the sidewalk to regulate the overflow from the LID facilities and pipe network. Underground culverts are connected to the pipe network, thus the stored rainwater can be discharged once the transmittability of the pipe network is recovered.

According to the designed storage volume of different subcatchments and features of the underlying surface, greenbelt inside and outside the red line of the avenue, rainwater reduction conditions (2- and 50-year return period) are all taken into consideration for rational LID facilities layout as well as interactive relations between LID facilities and pipe network. The details are demonstrated in Fig. 5.

\subsubsection{Determination of facility scale and assessment}

\section{(1) Calculation method}

$v_{k}=A_{s} \cdot\left(h_{1} \cdot \beta_{1}+h_{2} \cdot \beta_{2}+h_{3} \cdot \beta_{3}\right) \cdot \zeta$

In which, $\mathrm{V}_{\mathrm{k}}$ means the storage volume of the facility, $\mathrm{m}^{3}$; $\mathrm{A}_{\mathrm{s}}$ means covering area of the facility, ha; $\mathrm{h}_{1}$ means temporary water storage depth, $m ; h_{2}$ means planting soil depth of the facility, $\mathrm{m} ; \mathrm{h}_{3}$ means depth of protected aquifer, $\mathrm{m} ; \beta 1$, $\beta 2, \beta 3$ mean coefficient of effective storage volume determined according to medium porosity, moisture content and degree of compaction, etc., in this work $\beta 1=1, \beta 2=0.3$, $\beta 3=0.4 ; \zeta$ means volume reduction coefficient determined according to the effective cross-section area of the facility.

(2) Calculation of the control volume and verification

Taken No. 1 sub-catchment as an example, the control volumes of the designed facilities are determined as shown in Table 4. Using the identical method, control volumes of the five sub-catchments are figured out, and it is noted that calculated control volumes of various sub-catchments can meet the required storage volumes (shown in Table 3). The calculated total control volume with in Qinhuang Avenue is $2887.5 \mathrm{~m}^{3}$, 
Table 4 Control volume of LID facilities in No. 1 rainwater collection zone

\begin{tabular}{|c|c|c|c|}
\hline Type of facility & Area (ha) & Design parameters & $\mathrm{V}_{k}\left(\mathrm{~m}^{3}\right)$ \\
\hline $\begin{array}{l}\text { Ecological grassed waterway } \\
\text { (rainwater garden) }\end{array}$ & 0.11 & $\begin{array}{l}\text { Depth of stored water: } 0.2 \mathrm{~m} \text {, } \\
\text { depth of planting medium: } \\
0.5 \mathrm{~m} \text {, depth of gravel layer: } \\
0.4 \mathrm{~m}\end{array}$ & 384.85 \\
\hline $\begin{array}{l}\text { Transmission grassed waterway } \\
\text { I }\end{array}$ & 0.11 & Depth of stored water: $0.2 \mathrm{~m}$ & 152.46 \\
\hline $\begin{array}{l}\text { Transmission grassed waterway } \\
\text { II }\end{array}$ & 0.13 & Depth of stored water: $0.1 \mathrm{~m}$ & 57.20 \\
\hline Permeable pavement & 0.24 & Not included in the $V_{k}$ & 0 \\
\hline Total & & & 594.51 \\
\hline
\end{tabular}

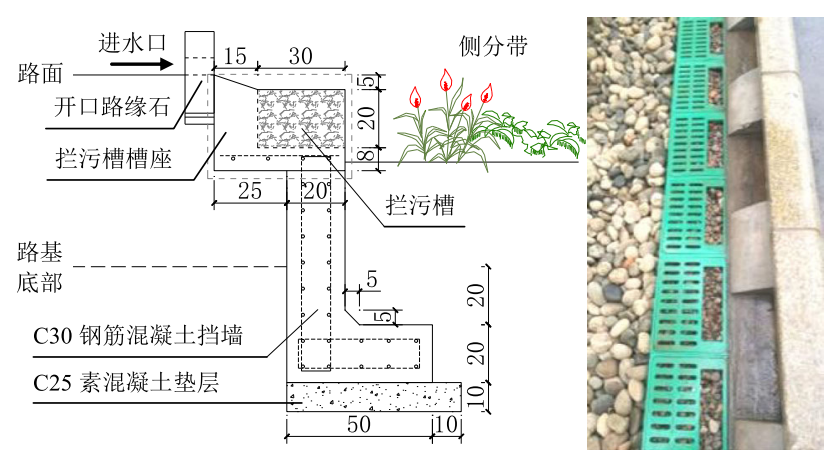

Fig. 6 Diagram of pollutants retention tank and reinforced concrete waterproofing wall

larger than the required total storage volume $\left(2851.6 \mathrm{~m}^{3}\right)$. As such a precipitation of $20.9 \mathrm{~mm}$ corresponding to an annual runoff control rate of $87 \%$ can be handled.

Moreover, after reconstruction the underlying surface consists of bituminous pavement, rigid pavement, permeable pavement and green belt. According to the area of various underlying surface and corresponding runoff coefficient, the comprehensive runoff coefficient is 0.721 , which is lowered down by 0.024 before reconstruction, indicating a certain decrease in the amount of collected rainwater.

\subsubsection{Detailed design and constructional method of representative LID facility}

(1) The LID facilities within the lateral zonation

a. Pollutants retention tank

It was observed that when rainwater flows along the curbstone openings into lateral zonation, lots of pollutants such as rubbish and clay will enter the lateral zonation as well causing surface harden and permeability reduction of the related LID facilities. Thus, pollutants retention tanks are constructed following curbstone openings, and 10-25 mm of carries made of construction wastes is filled in the tanks to retain contami- nates in the rain water and also to achieve energy dissipation (shown in Fig. 6).

b. Reinforced concrete waterproof wall

Given the potential risks caused by rain water invasion of the collapsible loess, as shown in Fig. 6 a L type reinforced concrete waterproof wall was designed and constructed to support the roadbed from the crossrange and also to prevent the infiltration of rainwater from the lateral zonation to the roadbed. The waterproof wall adopted C30 reinforced concrete with a length of $8 \mathrm{~m}$ and a bottom width of $50 \mathrm{~cm}$ as well as a varied height according to the neighbor LID facilities. Comparing with the conventional bricking and geotechnical cloth structures, reinforced concrete waterproof wall showed a better waterproof performance, higher bending moment and greater roadbed supporting effect. Further the waterproof wall is only constructed at the low point within the lateral zonation, thus the cost is $180-240$ yuan/m as the same as the conventional waterproof brick wall, which will not obviously increase the investment and also well resolve the contradictions between rainwater infiltration and roadbed safety.

c. Transmission grassed waterway

As presented in Fig. 7, the transmission grassed waterway locates at the rainwater inlet of the lateral zonation and structure foundation of trees and inspection well. The transmission grassed waterway has the same longitudinal slope as the road, with a concave surface covered by plats of 35 $50 \mathrm{~mm}$ and a primitive soil layer without artificial change. The antiseepage geotextile was used at the joint area between grassed waterway and roadway or side road.

d. Ecological grassed waterway (rainwater garden)

As presented in Fig. 8, the ecological grassed waterway is arranged at the end of the transmission grassed waterway within the lateral zonation. The ecological grassed waterway and rainwater garden have the identical structure except the length of replaced soil (rainwater garden showing a length of replaced soil less than $30 \mathrm{~m}$ ). From the top to bottom, it consists of covering layer, replaced layer and gravel layer. In detail, the covering layer in the top of soil contains tree 


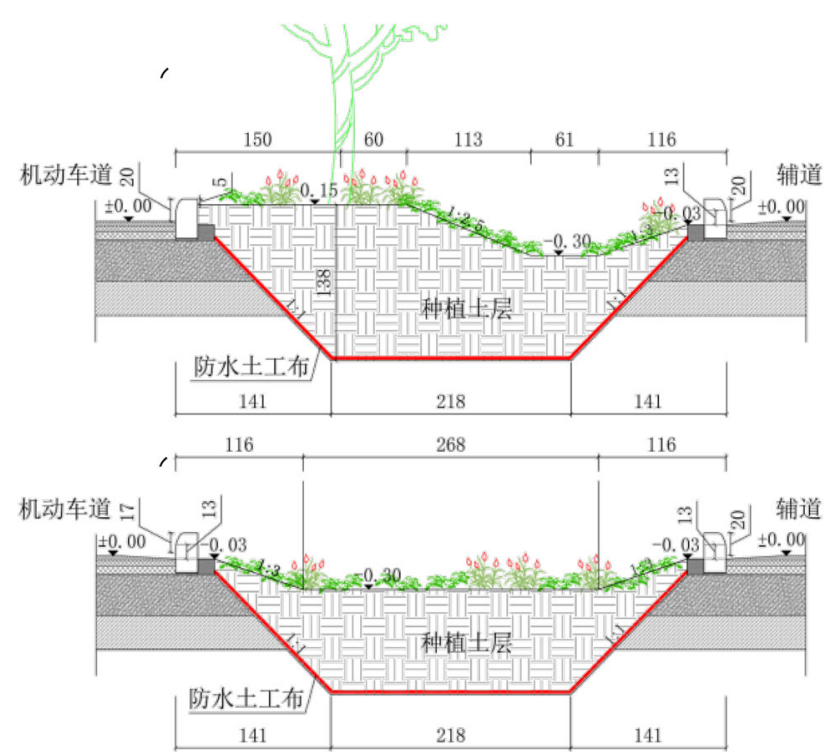

Fig. 7 Section graph of the transmission grassed waterway: a with tree and $\mathbf{b}$ without tree

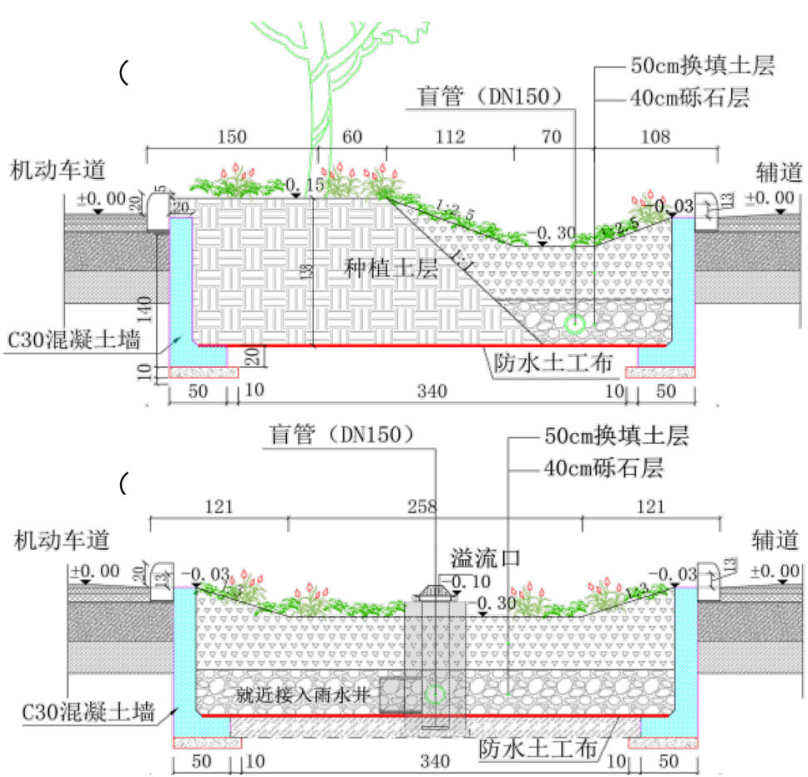

Fig. 8 Section graph of the ecological grassed waterway (rainwater garden): $\mathbf{a}$ with tree and $\mathbf{b}$ without tree

bark and sawdust with a thickness of $5 \mathrm{~cm}$, which is used for holding moisture in the soil and preventing surface harden. The replaced layer is not applied when the structure foundation of the tree and inspection and street lamp is encountered, which has a thickness of $50 \mathrm{~cm}$. The carriers in the replaced layer are from the mixture of coco coir, parent soil and coarse sand with a volume ratio of 40:40:20\%. Under the condition of natural compaction, replaced layer should have an initial permeability more than $150 \mathrm{~mm} / \mathrm{h}$, a stable permeability more than $70 \mathrm{~mm} / \mathrm{h}$, a TSS removal rate greater than $70 \%$

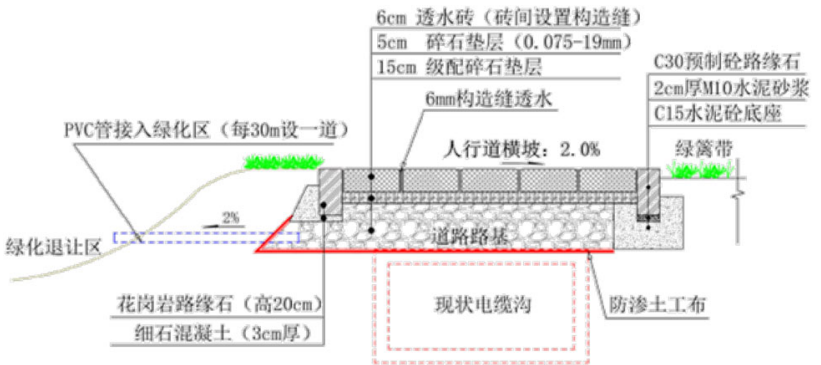

Fig. 9 Diagram of the permeable pavement
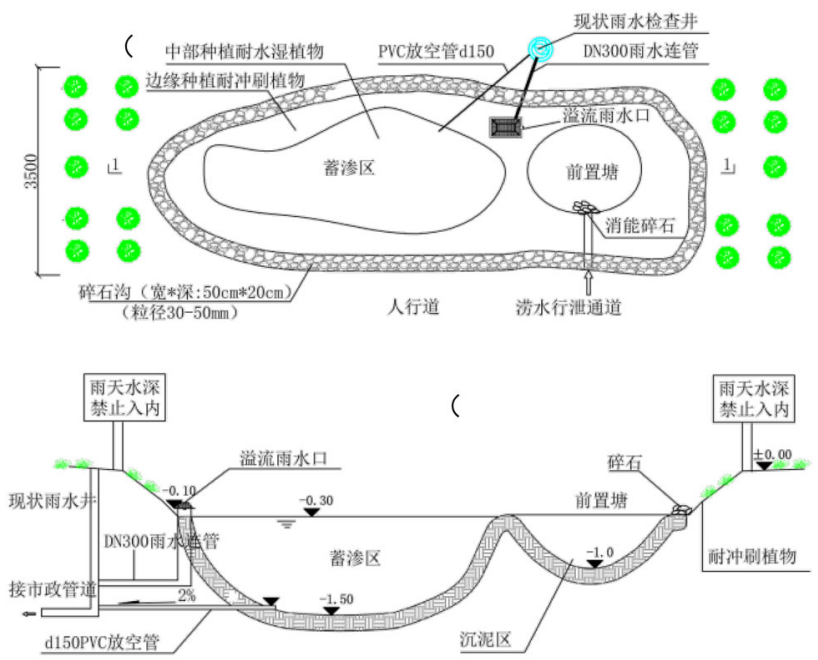

Fig. 10 Diagram of the rainwater regulating pond: a planar graph and b section graph

and be suitable for plant growth. The gravel layer is adopted for rainwater drainage with a thickness of $40 \mathrm{~cm}$. Permeable pipe is within the gravel layer and connected to the nearest overflow port and catch basin.

The ecological grassed waterway (rainwater garden) within the lateral zonation is designed for rainwater infiltration, retention, purification and delayed discharge. Moreover, when storm water occurs, the rainwater that can be discharged by the ecological grassed waterway will overflow to the pipe network.

It is worth noting that plant is also an important component of the LID facilities. During the reconstruction process, macrophanerophytes remain the same, while groundcover plants are selected based on the properties of flourished roots, superior purification ability, mainly indigenous plant coupled with certain alien species. As such, the integration between "sponge" and landscape functions can be achieved.

(2) The permeable pavement

The rigid pavement of the Qinhuang Avenue is changed to permeable pavement, meanwhile in the permeable layer drain-pipes are installed and linked with transmission grassed 
Fig. 11 Photos showing the changes of Qinhuang Avenue regarding the lateral zonation and waterlogging phenomenon before and after reconstruction

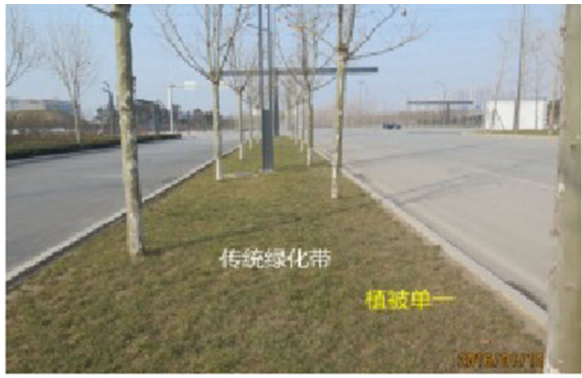

Lateral zonation (Before)

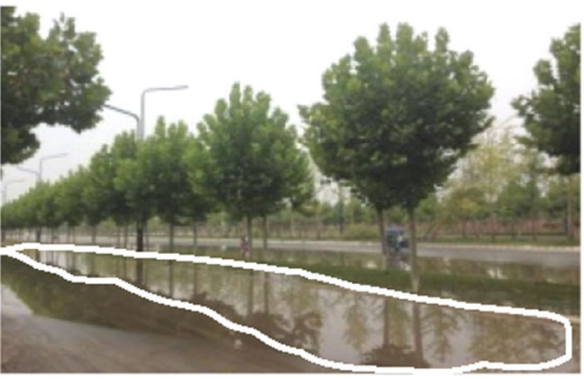

Waterlogging (Before)

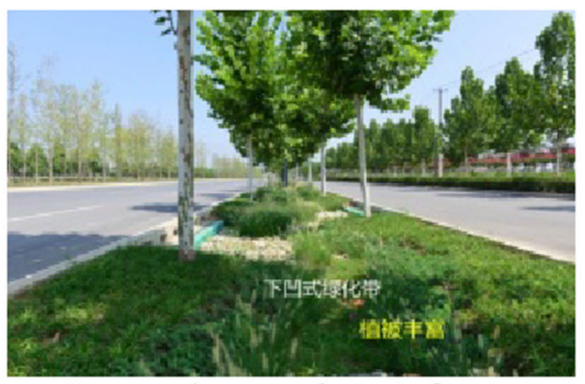

Lateral zonation (after)

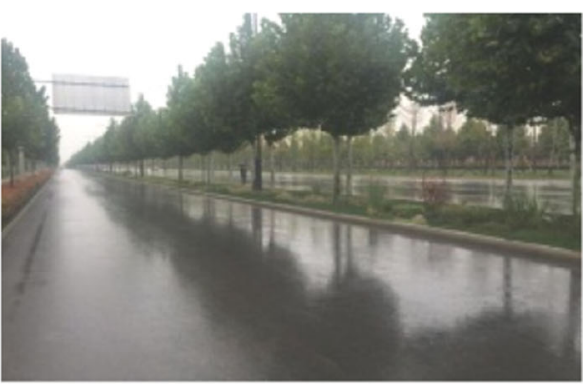

Non-waterlogging (after) waterway. Thus a complete system for rainwater infiltration and transmission is constructed (presented in Fig. 9).

(3) Drainage culvert and rainwater regulating pond

Along the Qinhuang Avenue there are five low points in elevation. Modeling results using SWMM software show that when a storm water of 50-year return period occurs three low points have great risks of waterlogging. Thus, at these locations drainage culverts under the sidewalk are constructed to induce the flood that cannot be timely eliminated to the greenbelt outside the road red line, where decentralized regulating ponds are constructed (shown in Fig. 10). The regulating pond contains two parts, namely, pretreatment zone as well as storage and infiltration zone. The stored flood can be discharged to the nearby catch-basin and rainwater pipe network through the empty pipe of the regulating pond. And also the rainwater that exceeds the overflow port in the regulating pond will be directly discharged into the pipe network.

\subsection{Performance after project reconstruction using LID technology}

\subsubsection{Perceptual images}

The photos that show the various grassed waterway, bioswale, typical approach for lateral zonation reconstruction and rainwater drainage system after construction are present in Figs. 11, 12 and 13.

\subsubsection{Analysis of annual runoff volume control rate}

As described previously, the designed runoff volume control rate is $85 \%$, which corresponds to a precipitation of $19.2 \mathrm{~mm}$. So the runoff volume control rate before and after reconstruction using LID technology is simulated using SWMM software. The results are presented in Fig. 14. Under conventional the develop mode the peak runoff rate is $0.32 \mathrm{~m}^{3} / \mathrm{s}$ while it is reduced to zero after reconstruction, indicating the designed requirement is completely met.

Further investigation is conducted to the runoff volume control rate when storm water of 50-year return period is encountered. Under the conventional develop mode the peak runoff rate is $2.63 \mathrm{~m}^{3} / \mathrm{s}$ while it is reduced to $2.23 \mathrm{~m}^{3} / \mathrm{s}$ after reconstruction with a reduction rate of $15.2 \%$. Moreover, the time for the peak runoff occurring is prolonged for $5 \mathrm{~min}$.

\subsubsection{Analysis of road waterlogging alleviation}

Before reconstruction of Qinhuang Avenue, there are three waterlogging points of water depth, waterlogging time and area more than $15 \mathrm{~cm}, 2 \mathrm{~h}$ and $500 \mathrm{~m}^{2}$ when the rainwater of 1or 2-year return period occurs. After reconstruction using LID technology, two waterlogging points is eliminated; meanwhile the condition of the left one is alleviated based on observational data, which is evidenced by the fact that the water depth, waterlogging time and area are decreased by 53, 85 and $70 \%$, respectively. 

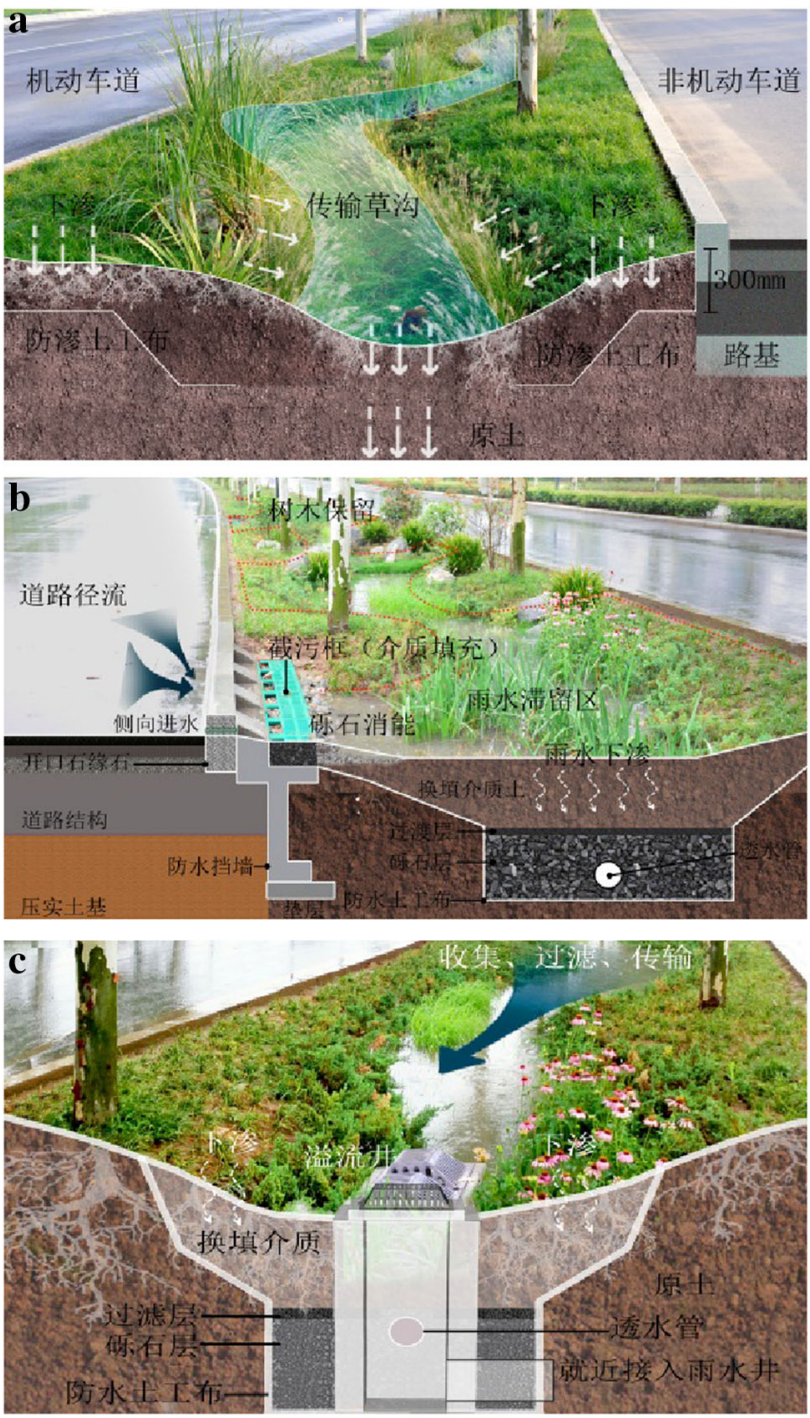

Fig. 12 Photos showing various grassed waterway and their connection to the drainage pipe network. a Transmission grassed waterway. b Ecological grassed waterway. c Connecting to the drainage pipe network

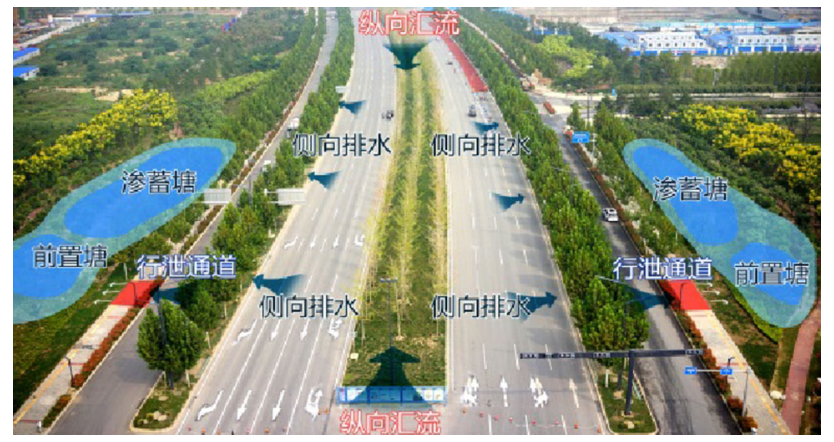

Fig. 13 Photos showing the of integrated drainage system within Qinhuang Avenue
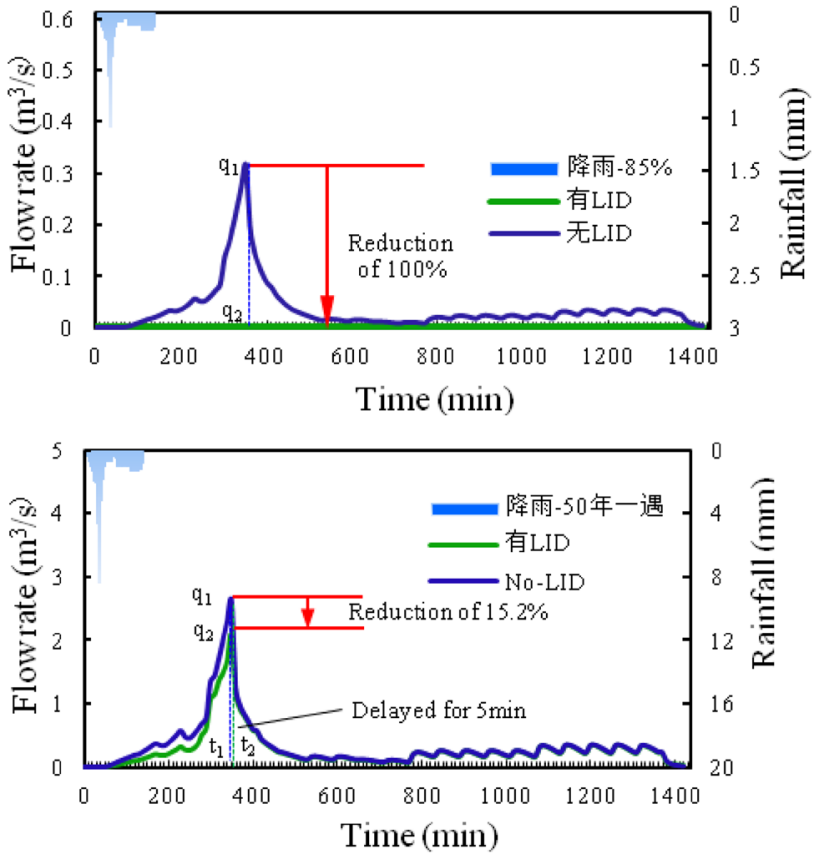

Fig. 14 Comparison of runoff control between traditional development mode and LID: a designed rainfall and b 50 year frequency rainfall

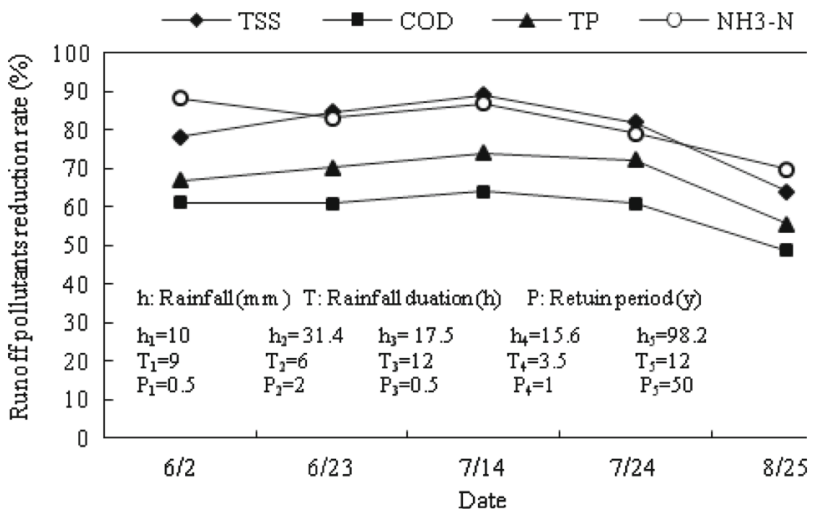

Fig. 15 Runoff pollutants reduction of LID facilities in the lateral zonation of Qinhuang Avenue

\subsubsection{Reduction of runoff pollution load}

After the completion of the main construction of Qinhuang Avenue, five rain runoffs are detected. The water quality analysis indicates that LID facilities within the lateral zonation shows obvious removal of TSS, TP, $\mathrm{COD}$ and $\mathrm{NH}_{3}$, with the removal rates of 64-89, 56-74, 49-64, and 70-88\%, respectively (shown in Fig. 15). 


\section{Conclusions}

The reconstruction project of Qinhuang Avenue was partially completed according to the LID technology and satisfied sponge effect was demonstrated through preliminary monitoring and simulation analysis. The main conclusions could be drawn as follows:

(1) Simulation results indicated that the total annual runoff control rate reached $87 \%$, and 50-year return period rainfall peak flow in $24 \mathrm{~h}$ was lower by $15.2 \%$, effectively reducing the drainage pressure on downstream pipe network and pump station.

(2) Pollution removal rates were tested by field measurement as follows: TSS of $64-89 \%$, COD of $49-64 \%$, TP of 56$74 \%$ and $\mathrm{NH}_{3}$ of $70-88 \%$, which indicated the effective source control of runoff pollution and the reduction in pollution risk of receiving water bodies.

(3) Water accretion phenomena were largely avoided as evidenced by no apparent water accumulation under small and medium rainfall. With the improvement of downstream pipe network and pumping station, the capacity for drainage and preventing waterlogging will be further enhanced.

(4) The issues limiting the utilization of LID (such as the geology of collapsible loess and the poor infiltration problem) were well solved by using the technologies such as the reinforced concrete retaining wall supporting method and artificial replacement of the carrier in the biological retention facilities. Further optimization and improvement of the constructed project will be carried out based on the long-term monitoring and simulation results.

Acknowledgements This study was supported by the National Natural Science Foundation of China (Grant Nos. 51378423 and U1501253) and Science and Technology Planning Project of Guangdong Province, China (Grant No. 2016B010127005).

Open Access This article is distributed under the terms of the Creative Commons Attribution 4.0 International License (http://creativecomm ons.org/licenses/by/4.0/), which permits unrestricted use, distribution, and reproduction in any medium, provided you give appropriate credit to the original author(s) and the source, provide a link to the Creative Commons license, and indicate if changes were made.

\section{References}

1. Kundzewicz, Z.W., Kanae, S., Seneviratne, S.I., Handmer, J., Nicholls, N., Peduzzi, P., Mechler, R., Bouwer, L.M., Arnell, N., Mach, K., Muir-Wood, R., Brakenridge, G.R., Kron, W., Benito, G., Honda, Y., Takahashi, K., Sherstyukov, B.: Floodrisk and climate change: global and regional perspectives. Hydrol. Sci. J. 59(1), $1-28(2014)$
2. Wang, Y., Sun, M., Song, B.: Public perceptions of and willingness to pay for sponge city initiatives in China. Resour. Conserv. Recycl. 122, 11-20 (2017)

3. Xia, J., Zhang, Y., Xiong, L., He, S., Wang, L., Yu, Z.: Opportunities and challenges of the Sponge City construction related to urban water issues in China. Sci. China Earth Sci. 60, 652-658 (2017)

4. Qiu, B.X.: The connotation, approach and perspective of Sponge city and LID. Water Wastewater Eng. 41, 1-7 (2015). (in Chinese)

5. Dietz, M.E.: Low impact developmentment practices: a review of current research and recommendations for future directions. Water Air Soil Pollut. 186(1), 351-363 (2007)

6. Wang, L., Lyons, J., Kanehl, P., Bannerman, R.: Impacts of urbanization onstream habitat and fish across multiple spatial scales. Environ. Manag. 28(2), 255-266 (2001)

7. Chow, M.F., Yusop, Z., Shirazi, S.M.: Storm runoff quality and pollutant loading from commercial, residential, and industrial catchments in the tropic. Environ. Monit. Assess. 185, 8321-8331 (2013)

8. Huber, M., Welker, A., Helmreich, B.: Critical review of heavy metal pollution of traffic area runoff: occurrence, influencing factors, and partitioning. Sci. Total Environ. 541, 895-919 (2016)

9. Kaur, T., Chana, Inderveer: Energy aware scheduling of deadlineconstrained tasks in cloud computing. Cluster Comput. 19(2), 679698 (2016)

10. Kang, S., Kang, S.: The study of exercise and health services platform for prevention of dementia. Cluster Comput. 20(1), 867-872 (2017)

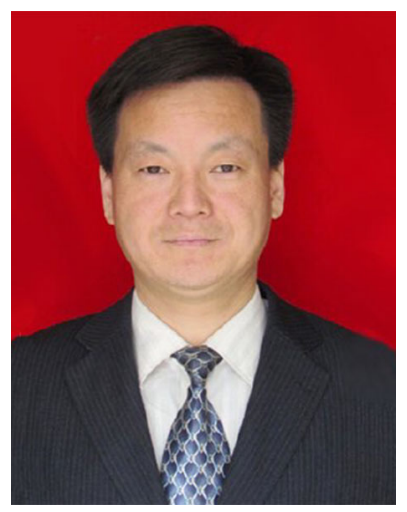

Pengbo Hu was born on November 23, 1976 in Xianyang, Shaanxi province. In 2014, he was studying for a doctorate in system engineering in the Automation College of Northwestern Polytechnic University. At present, he is the deputy general manager of the Investment and Development co., LTD in Fengxi New City of Xixian New District. His main research interests are the integration and modeling of water resources in sponge city.

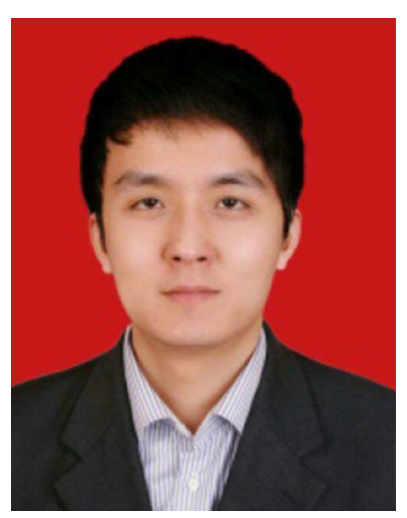

Yue Ma was born on April 13th, 1986 in Yan'an, Shaanxi privince. In 2012, he graduated from School of Environmental and Municipal Engineering in Xi' an University of Architecture and Technology with master's degree. At present, he is the director of basic research department at sponge city technology research center in Fengxi New City Development and Construction Group Co., Ltd of Shaanxi Xixian New District. His main research interests are water supply and drainage as well as urban stormwater management. 


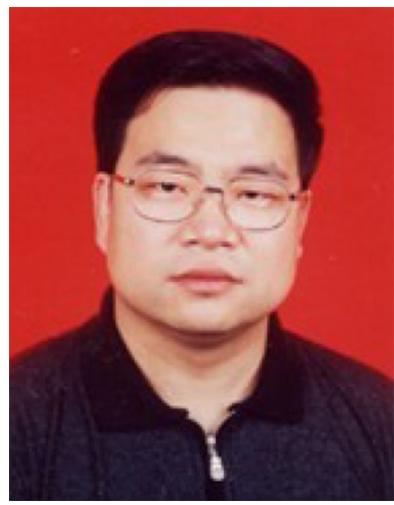

Huifeng Xue born June 16, 1964, in ShanxiYuncheng Current position, grades: professor in Northwestern Polytechnical University. University studies: $\mathrm{PhD}$ degree in Water resource economics from Xi'an Polytechnic in 1995. Scientific interest: the modeling of complex systems, Simulation and performance evaluation, management, systems engineering, energy and environmental systems engineering, computer control, intelligent control, network control.

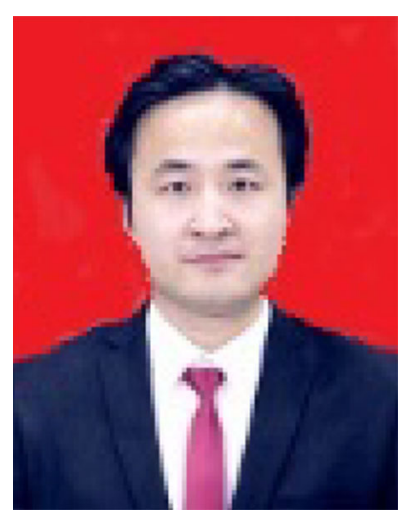

Feng Zhang was born in Shannxi Yulin on June 26, 1980, received the MS degree in Computer science from Xidian University in 2009. Now he is a $\mathrm{PhD}$ of Northwestern Polytechnical University. He is currently a professor in Yulin University. His research interests are in the areas of Cloud integrated manufacturing technology, the modeling of complex systems, the Internet of Things applications. 